\title{
PRÁTICAS DE ENSINO CRÍTICAS DE COMPETÊNCIA EM INFORMAÇÃO, MÍDIAS E TECNOLOGIAS DIGITAIS E A DESCONSTRUÇÃO DE ESTEREÓTIPOS DE GÊNERO
}

\author{
CRITICAL INSTRUCTION PRACTICES OF \\ INFORMATION, MEDIA AND DIGITAL LITERACIES AND \\ THE DECONSTRUCTION OF GENDER STEREOTYPES
}

Andréa Doylea

Gilda Olintobc

\begin{abstract}
RESUMO
Objetivo: O trabalho apresenta uma síntese da tese de doutoramento que teve por objetivo entender como se ensina competência crítica em informação, mídias e tecnologias digitais de modo a favorecer a desconstrução de estereótipos de gênero. Metodologia: Os métodos usados na abordagem empírica incluem a Revisão Sistemática de Literatura e a Análise de Conteúdo, com categorias analíticas construídas a partir do método transdisciplinar Mapa Teórico Conceitual. Resultados: Os resultados incluem um panorama internacional de 65 práticas de ensino críticas, assim como a análise das 23 práticas de ensino de competências críticas que também trabalham com estereótipos e gênero. Conclusões: A análise dos dados permite concluir que para desconstruir estereótipos de gênero por meio do ensino de competências em informação, mídias e tecnologias digitais são necessárias atividades que considerem diversos pontos de vista, promovam autocrítica, sejam colaborativas, voltadas para a desconstrução de opressões, favoreçam o empoderamento e englobem uma luta contínua por justiça social e bem viver entre pessoas e com a natureza.
\end{abstract}

Descritores: Competência em informação. Estereótipo de gênero. Práticas de ensino críticas. Feminismo.

\footnotetext{
a Doutora em Ciência da Informação pela Universidade Federal do Rio de Janeiro (IBICT/UFRJ). E-mail: andrea@hibrida.art.br

b Doutora em Comunicação e Cultura pela Universidade Federal do Rio de Janeiro. (IBICT/UFRJ). Docente do Programa de Pós-Graduação em Ciência da Informação da Universidade Federal do Rio de Janeiro (IBICT/UFRJ). E-mail: gildaolinto@gmail.com

c O presente trabalho é derivado de pesquisa de doutoramento realizada com apoio da Coordenação de Aperfeiçoamento de Pessoal de Nível Superior - Brasil (CAPES) - Código de Financiamento 001
} 


\section{INTRODUÇÃO}

O presente trabalho apresenta aspectos indispensáveis do enfoque teórico e da abordagem empírica da tese de doutoramento defendida em março de 2021 (DOYLE, 2021). Estão aqui descritos os principais referenciais teóricos mobilizados, que incluem estudos de Gênero e estudos sobre Competência em Informação (Colnfo), buscando estabelecer a relação entre esses dois temas, com ênfase no ensino das Tecnologias de Informação e Comunicação (TIC) com vistas à desconstrução de estereótipos.

A pesquisa segue uma tendência de estudos de informação e gênero que vêm ganhando cada vez mais destaque no Brasil. Antes dos anos 2000, a Base de Dados Referencial de Artigos de Periódicos em Ciência da Informação (BRAPCI) lista 19 trabalhos a partir do descritor "gênero". Hoje ${ }^{1}$, já se recupera nesta base 487 trabalhos com essa temática na Ciência da Informação $(\mathrm{Cl})$, o que mostra um imenso desenvolvimento e um crescente interesse por parte de pesquisadoras e pesquisadores.

Para pensarmos uma Ciência da Informação empenhada em promover a equidade de gênero, atentamo-nos para os conceitos de gênero e de informação. O conceito de gênero vem rejeitar o determinismo biológico em torno das noções de feminino e masculino e sublinhar o caráter fundamentalmente social das distinções de sexo, de acordo, entre outras, com Joan Scott (1995). Ou seja, gênero é uma construção social que não se desprende do corpo sexuado, mas traz o debate para o campo social que é onde se constroem e se reproduzem as desigualdades, como destaca Guacira Louro (1997).

Essa noção de construção social também se aplica ao conceito de informação, visto que essa investigação se reconhece dentro do paradigma social de Rafael Capurro (2003). Assim, a informação nem é vista como objetiva (paradigma físico), nem é subjetiva, sendo construída na mente de quem a processa (paradigma cognitivo). A Ciência da Informação contemporânea entende que a informação é construída socialmente, na intersubjetividade das atividades entre pessoas, registros de conhecimento e seus diversos contextos,

\footnotetext{
${ }^{1}$ Consulta feita no dia 26 de janeiro de 2021.
} 
como argumenta Carlos Alberto Ávila do Araújo (2018).

A pesquisa parte da premissa de que a informação, as mídias e as tecnologias, se apreendidas a partir do ensino e do desenvolvimento de uma competência crítica, podem contribuir para que a pessoa se fortaleça individual e coletivamente e atente, também, para questões de justiça social. Se, a partir do aprendizado dos modos de construção da informação/mídias/tecnologias (com seu poder de mostrar, ocultar e direcionar), esse entendimento puder ser extrapolado para o de outras questões sociais, então talvez o ensino da informação possa contribuir para a redução de inequidades de gênero, por exemplo.

Inversamente, os estudos de gênero também podem ajudar a construir uma visão mais crítica da informação, mídias e tecnologias digitais. Teorias feministas, entendidas como ferramentas de reflexão e explicação da realidade, podem ampliar os ângulos de visão, propor novas abordagens e oferecer soluções para problemas relacionados às TICs.

A partir desse entendimento, perguntamo-nos: como se ensina competência crítica em informação, em mídias e em tecnologias digitais? E, considerando nosso delineamento da noção de crítica a partir de um olhar feminista, completamos: as práticas críticas de ensino de literacias da informação ou, para usar o termo sugerido pela Organização das Nações Unidas para a Educação, a Ciência e a Cultura (UNESCO), Alfabetização Midiática e Informacional (AMI) têm envolvido questões de gênero? Que recursos são ou poderiam ser utilizados para o desenvolvimento das competências críticas em informação, mídias e tecnologias digitais de modo a promover a desconstrução de estereótipos de gênero?

Com base nessas indagações, nosso objetivo geral foi identificar e analisar a literatura sobre ensino de competências em informação, mídia e tecnologias digitais a partir de uma postura crítica e feminista e detectar de que forma elas podem subsidiar propostas de desconstrução de estereótipos de gênero. Já os objetivos específicos são: a) revisitar os conceitos de competência em informação, mídia e tecnologia digital, buscando identificar seus diferentes olhares, suas vizinhanças acadêmicas e a suas dimensões críticas; b) delinear 
o conceito de crítica a partir de um olhar feminista; c) mapear práticas críticas de ensino de competências em informação, mídias e tecnologias digitais; e, d) analisar as práticas de ensino de AMI que envolvem gênero e/ou a desconstrução de estereótipos.

$\mathrm{Na}$ sequência, apresentamos o referencial teórico, seguido dos procedimentos metodológicos, resultados obtidos e considerações finais.

\section{REFERÊNCIAL TEÓRICO}

Na primeira parte dessa seção, mobilizamos, inicialmente, literatura sobre Competência em Informação (Colnfo), assim como sobre a subárea da Competência Crítica em Informação (CCl). Depois, propomos um olhar para as áreas vizinhas para falar de mídia-educação, letramento digital e explorarmos conceitos transversais como o de literacia, transliteracias, Alfabetização Midiática e Informacional (AMI) e habilidades do século XXI.

Já na segunda parte, revisamos literatura sobre estereótipos de gênero e os prejuízos que eles causam (negação, invisibilização, objetificação, violência simbólica e física), seguida de discussão com teorias feministas, como as de saber localizado de Donna Haraway (1988), lugar de fala de Djamila Ribeiro (2018), bem viver de Julieta Paredes (2015) e de educação transgressora de bell hooks (2019), que destaca a pedagogia crítica de Paulo Freire (1987). Por fim, promovemos uma análise do método interdisciplinar de conceituação de Vera Dodebei.

\subsection{CompetênCIA Em InformaÇão, Mídia e TeCnOlogias Digitais, Suas Críticas E CONVERGÊNCIAS}

Os estudos sobre Competência em Informação (Colnfo) têm origem na educação de usuários dos anos 1950, se desenvolvem nos anos 1980 e entram para a literatura científica nacional na virada do milênio, como destaca Bernadette Campello (2003). Eles se preocupam em ensinar pessoas a lidar com sistemas de informação e com os novos recursos TIC (buscas em catálogos, bases de dados e outros recursos de bibliotecas e unidades de informação), a 
avaliar criticamente as informações recuperadas e selecionar as referências que melhor atendem a suas necessidades. Pesquisadoras brasileiras, pioneiras na abordagem do tema, como Elisabeth Dudziak (2003), Regina Belluzzo (2017) e Maria Helena Hatschbach e Gilda Olinto (2008) trazem importantes contribuições como as ideias de aprender a aprender e o aprendizado ao longo da vida, fundamentais para o tema no campo da $\mathrm{Cl}$.

Apesar do pensamento crítico ser parte fundamental das principais concepções de Colnfo, alguns pesquisadores reforçam a necessidade de se dar atenção aos elementos contextuais e aos sistemas de poder em torno da informação. Eles também voltam o olhar para os métodos e objetivos de uma educação direcionada para a emancipação social. Destacamos os estudos sobre competência crítica em informação de James Elmborg (2006) e Eamon Tewell (2015). No Brasil, o tema é inaugurado por Vitorino e Piantola (2009) e desenvolvido por Anna Brisola e Nathália Romeiro (2018).

Com um olhar mais transversal, Beatrice Rosa (2016) mostra a complementaridade dos campos da competência em informação, da educação midiática, do letramento digital e da educação. A partir de marcos normativos internacionais, a autora contribui para dar consistência ao conceito guarda-chuva Alfabetização Midiática e Informacional (AMI). Promovida pela Unesco, a AMI é uma forma de agrupar e socializar os esforços dessas áreas vizinhas (Ciência da Informação, Comunicação Social, Computação e Educação).

$\mathrm{Na}$ Comunicação Social, a ideia de media literacy ou Mídia-Educação, surge na década de 1980 com a Declaração de Grünwald (UNESCO, 1982). Uma série de programas, institutos e congressos começam a ser desenvolvidos em diversos países e resultam em importantes trabalhos como o relatório de Patrícia Aufderheide (1993) e, mais tarde, as pesquisas sobre convergências entre mídias tradicionais e digitais de Sônia Livingstone (2004).

O desenvolvimento da internet e dos computadores pessoais nos anos 90 do século passado faz surgir também a proposta de uma competência que, entre diversas nomenclaturas, chamamos de Letramento Digital. Paul Gilster (POOL, 1997) cunha o termo digital literacy entendendo que a capacidade de usar equipamentos digitais, junto com uma visão crítica de tais usos, seria 
fundamental para a participação na sociedade conectada.

Finalizamos as discussões sobre competências apresentando outro termo convergente, a ideia de transliteracias entendidas como um processo de trânsito entre as diversas literacias de Frau-Meiggs (2012). Já para reunir esses fartos conjuntos de pesquisas em torno de seus elementos inter-relacionados, Unesco propõe o termo Media and Information Literacy que "é essencial para empoderar pessoas com conhecimento crítico sobre as funções das mídias, os sistemas de informação e os conteúdos que oferecem" (UNESCO, 2010, p. 11).

\subsection{Teorias Críticas Feministas e Estereótipos de Gênero}

A informação, da mesma forma que a educação, a ciência, as mídias e as tecnologias não são neutras. Elas são produzidas por pessoas/grupos em contextos sociais específicos e refletem suas possibilidades, limitações e objetivos, tanto em sua constituição quanto no seu efeito, tornando-as obrigatoriamente circunstanciais, parciais e localizadas. Essas afirmações têm base em diversas teorias críticas, dentre as quais nos interessam especialmente aquelas produzidas por e alinhadas com os movimentos feministas.

Tais teorias buscam mostrar, nos mais diversos campos de conhecimento, que as tendências advindas dessas parcialidades têm um impacto profundo no modo como pensamos, sentimos e projetamos nossas ambições, ou seja, tanto no plano das ideias quanto nas condições cotidianas de vida das pessoas. Donna Haraway (1988) e Djamila Ribeiro (2017) são exemplos de autoras que denunciam a premissa da neutralidade/objetividade como mecanismo de dominação patriarcal da sociedade/ciência/discurso. Dialogamos sobre patriarcado com Heleieth Saffiotti (2011) e com o feminismo comunitário de Julieta Paredes (2015) mostrando sua luta pelo fim desse sistema injusto e injustificável.

$\mathrm{Na}$ academia ou nos movimentos sociais, a exposição dos diversos níveis de opressão e violência a que as mulheres são submetidas, do silenciamento à piada, do menosprezo ao assassinato é fundamental para que seja desnaturalizada. $O$ ponto de vista $e$ as reflexões que essas experiências proporcionam a homens e mulheres nunca é o mesmo. A ideia de lugar de fala 
(RIBEIRO, 2017) vem justamente estabelecer o posicionamento social, histórico, cultural de quem está falando para que quem está lendo/ouvindo possa localizar esse saber (HARAWAY, 1988).

O estereótipo de gênero é, para Maria D’Amorim (1997), o conjunto de ideias, de uma pessoa ou grupo social, sobre as características de homens e mulheres. Guacira Louro (1997) acrescenta que, mais do que as características dos gêneros, é o valor atribuído a elas que importa para a fabricação das desigualdades. O que discutimos aqui é como o estereótipo da mulher como sexo frágil, do lar, passiva, emotiva, carinhosa, cuidadora etc. traz prejuízos concretos para as mulheres em quase todos os aspectos da vida social.

Assim, se a liderança é uma qualidade mais valorizada no mercado de trabalho, e essa característica é "naturalmente" atribuída a homens, compreende-se que eles sejam favorecidos na hora da escolha para posições de gestão. Ainda hoje, "meros $3 \%$ dos presidentes e $5 \%$ dos presidentes de conselho das 250 maiores empresas brasileiras são do sexo feminino", mostra o relatório de Batista e Mattos (2019, p. 5).

Identificamos quatro grandes tipos de trabalhos sobre estereótipos de gênero: aqueles que estudam seu estabelecimento na primeira infância, os que apontam os mecanismos de reprodução social desses estereótipos (negação, invisibilização, objetificação), os que focalizam as suas consequências (teto de vidro e violência simbólica e física) e os que trazem ações de desconstrução.

$O$ conjunto desses estudos mostra o aspecto multi-dimensional e indiscutivelmente prejudicial dos estereótipos de gênero, fornecendo a primeira justificativa para a escolha desse tema. O segundo argumento é que os estereótipos de gênero, por serem culturalmente transmitidos por gerações desde a mais tenra infância e se misturarem com nossas próprias identidades (LOURO, 1997), são muito persistentes na vida social. Daí surge a necessidade de se pensar em mecanismos para a desconstrução desses estereótipos.

As ideias de conscientização, emancipação e autonomia vêm da pedagogia crítica de Paulo Freire (1987), que propõe que as pessoas tenham seus conhecimentos prévios valorizados, sejam estimuladas a serem sujeitos da sua própria aprendizagem, para deixarem de ser tratadas como cabeças vazias 
nas quais o conhecimento é depositado. bell hooks (2019) adota, mas também critica e completa essa proposta, trazendo para sua sala de aula debates sobre misoginia, racismo e outras violências partir da criação, em suas turmas, de comunidades de aprendizado pautadas na escuta, na empatia e no afeto.

Por fim, para circunscrever a ideia de prática de ensino feminista, usamos método interdisciplinar de construção conceitual desenvolvido por Vera Dodebei (1997). Reagrupamos três dimensões do que entendemos como crítica: ela pode estar na origem de uma prática e se constituir sob a forma de autocrítica, por exemplo; ela pode se apresentar como processo, aparecendo na escolha dos métodos de ensino; ou ela pode se localizar nas finalidades de uma proposta pedagógica e ter como objetivos a emancipação e autonomia das pessoas envolvidas.

A seguir, explicitamos os percursos da pesquisa empírica.

\section{PERCURSOS METODOLÓGICOS}

Para os metodólogos Petticrew e Roberts (2006), a revisão sistemática de literatura (RSL) é um método para se obter respostas a partir um grande corpo de estudos, cuja principal vantagem é a redução de viés ao lidar com grandes massas de dados. Adotamos um tipo específico de RSL, o mapeamento sistemático de literatura (MSL).

O Mapeamento Sistemático de Literatura (MSL) é um método de revisão de literatura de caráter exploratório, que ajuda a estabelecer um panorama de estudos que respondem a uma interseção de campos, conforme Heinz (2014). No caso aqui, trata-se do ensino das competências abarcadas pela Alfabetização Midiática e Informacional (AMI) filtrado pela ideia de prática de ensino crítica.

Ao estabelecer o conceito de crítica a partir do olhar feminista, e defini-lo como fio condutor da pesquisa, optamos inicialmente por mapear todos os estudos que relatam práticas de ensino de competências em informação/mídias/tecnologias, sendo eles sobre gênero/estereótipos ou não. A proposta foi encontrar trabalhos da $\mathrm{Cl}$, da Comunicação, da Computação e da Educação que respondessem ao critério inicial 'prática de ensino crítica'. 
Após revisão conceitual e alguns testes nas bases, selecionamos uma série de termos em inglês para dar conta das convergências entre as áreas TIC: tecnologia, informação e comunicação. Junto com information literacy e library literacy/skills, incluímos media literacy e news literacy assim como digital literacy, computer literacy e ICT literacy. Como esta iniciativa é transdisciplinar, incluímos os termos transliteracy/ies e 21st century literacy/skills que define exatamente 0 entendimento deste trabalho sobre a competência em informação: uma habilidade fundamental para a pessoa do século XXI.

Nas 4 bases selecionadas, a saber, Web of Science e Scopus (que juntas têm amplitude suficiente para um panorama da literatura científica internacional), SciElo (com foco na América Latina) e ERIC (especializada em Educação), foram recuperados 353 estudos cujo resumo foi lido. Aplicados os critérios prédefinidos $^{2}$, procedemos à leitura do texto integral de 94 trabalhos. Após nova rodada de inclusões e exclusões, recuperamos 65 estudos que mostram atividades pedagógicas aplicadas, feitas para ensinar competência crítica em informação, mídia e/ou tecnologias digitais.

A coleta de dados aconteceu em setembro de 2019 e a análise dos dados coletados aconteceu entre novembro de 2019 e em janeiro de 2020. Esse corpus de 65 trabalhos foi analisado com o uso de princípios da análise de conteúdo para pesquisas qualitativas (BARDIN, 2011). A planilha de codificação, que visou caracterizar o conjunto dos 65 trabalhos descrevendo atividade pedagógicas voltadas para o desenvolvimento da AMI, tem 14 tipos de registro, a saber: número de participantes, nível educacional, duração (em horas e semanas), região (cidade e país), campo do conhecimento, campo AMI, teorias/conceitos mobilizados, métodos usados, objetivos, produtos, resultados, tema social discutido, dimensão crítica e ideia geral.

$\mathrm{Na}$ segunda etapa da pesquisa, ocorrida entre novembro e janeiro de 2021, revisitamos os 65 trabalhos para extrair aqueles que pudessem nos ajudar responder nossa questão de pesquisa: como se dá, na prática, e que recursos

2 Critérios técnicos: eliminação de repetições; formatos longos (livros, teses inteiras); indisponíveis online. Critérios conceituais: eliminação de trabalhos que não tinham nenhum elemento crítico; não envolviam as Tecnologias de Informação e de Comunicação (TIC); não eram estudos primários; ou não foram aplicados. 
acionam, as experiências de ensino crítico de competências em informação, mídias e tecnologias digitais com vistas à desconstrução de estereótipos e redução de desigualdades de gênero?

Visto que nosso interesse de pesquisa é entender como fazer, ou seja como o ensino crítico subsidia a desconstrução de estereótipos de gênero, construímos 6 categorias de análise a partir da junção de princípios convergentes entre as teorias e pedagogias feministas e as teorias e recomendações dos estudos de competências em informação, mídias e tecnologias digitais. Essas categorias serão detalhadas na seção a seguir.

A construção das categorias de análise se pautou no método transdisciplinar Mapa Teórico-Conceitual (MTC) desenvolvido por Vera Dodebei (1997). No eixo horizontal, entendido como elemento contextual de cada pesquisa, as etapas do ciclo de vida do objeto, inicialmente empregadas por Dodebei (1997), foram substituídas por lugares oriundos das perguntas de Anielle Franco (2020): a) de onde viemos (Origem); b) Onde estamos (Processo) e c) Para Onde Vamos (Objetivo). O método foi reutilizado para as necessidades da pesquisa, mostrando-se ser uma ferramenta útil para a organização dos conceitos oriundos das teorias feministas, além de ser consistente para a construção conceitual em situações transdisciplinares (DOYLE; DODEBEI, 2021).

Para a etapa de categorização, partimos de uma filtragem por tema social. Por tema social entendemos debates voltados para a promoção de igualdade social, especificamente voltados para grupos desprivilegiados, como grupos étnico-raciais, classe social, de gênero, etc. Tais temas podem e devem ser integrados ao ensino de informação, mídias e tecnologias. No caso dessa pesquisa, interessam especialmente os debates em torno do tema social gênero, seja ele sobre machismo estrutural, violência contra mulheres, objetificação em propagandas, entre diversos outros aspectos.

Assim, com os descritores gênero, feminismo e estereótipos, selecionamos os trabalhos que trazem os aportes mais relevantes para a nossa pesquisa. Esses 23 trabalhos, que representam 1/3 do corpus total, foram tratados com o software Atlas.ti, versão 9. Ele processa os textos selecionados 
em busca das palavras-chave, seleciona o trecho em que há uma ocorrência e permite que se atribua uma categoria para o trecho.

A seção a seguir apresenta os resultados da primeira fase da pesquisa empírica, o Mapeamento Sistemático da Literatura com seus 65 trabalhos. Em um segundo momento, trazemos as conclusões das análise das 23 práticas de ensino que, além de favorecem um melhor entendimento das questões informacionais, comunicacionais e tecnológicas, também podem contribuir para uma mudança no modo de ver as relações de gênero na sociedade.

\section{PRÁTICAS DE ENSINO CRÍTCAS DE AMI E SEU DIRECIONAMENTO PARA A SUPERAÇÃO DE ESTEREÓTIPOS DE GÊNERO}

O foco empírico deste estudo visou traçar um panorama internacional de práticas de ensino críticas. Esta seção se organiza em três momentos, assim como a pesquisa: o mapeamento sistemático da literatura, a construção de categorias de análise e a análise qualitativa das práticas pedagógicas que, além de proporcionarem uma visão crítica da informação das mídias e das tecnologias, também trabalharam a desconstrução de estereótipos de gênero.

\subsection{O Mapeamento Sistemático da Literatura Sobre Práticas de Ensino CRíticas de AMI}

Para sistematizar a análise inicial, cada experiência foi classificada nos seguintes aspectos: 1 . Identificação: quem (participantes, área do conhecimento) e onde fez (local, nível de ensino); 2. Abordagem teórico-metodológica: teorias acionadas e recursos metodológicos utilizados, ou seja, como foi feito; e 3. Particularidades: se as práticas abordam algum tema social e quais dimensões críticas as informam.

No que se refere ao primeiro grupo, dos aspectos identitários, encontrouse projetos que envolveram de 2 a 500 participantes; em níveis escolares que vão da alfabetização ao mestrado; e em contextos escolares/universitários, paraescolares (projetos complementares, aulas depois do horário) e extra-escolares (centros comunitários, centros de educação especial). As durações dos 
programas vão de uma sessão de 2 horas a projetos multidisciplinares, sendo a maior parte deles desenvolvida ao longo de um semestre.

Ainda sobre quem desenvolveu esses projetos, quanto aos campos do conhecimento, eles vão da Química à Psicologia, da Engenharia à Nutrição, da Agricultura à Administração, ainda que a maior parte das iniciativas, fora das áreas da AMI, seja da área das Línguas. Os projetos relatados encontram-se distribuídos pelos 3 campos AMI, com uma concentração maior na Comunicação, seguida pelas Tecnologias e pela área da Informação, sendo que apenas $30 \%$ deles se identifica como crítico em seu campo AMI (critical media literacy, critical digital literacy ou critical information literacy).

Já no segundo tipo de classe, a dos aspectos teórico-metodológicos, as principais fundamentações teóricas mencionadas são obras de Paulo Freire disparado na frente, seguido por David Buckingham, Donna Alvermann, Renée Hobbs, Douglas Kellner, Jeff Share e bell hooks. Já no que diz respeito às atividades desenvolvidas em classe, as mais usadas são: trabalho em grupo, discussões grupo, leitura crítica e análise de conteúdo/discurso, workshops práticos, projeção de vídeos e avaliação de informação, ou seja, as atividades didáticas privilegiadas são dialógicas, interativas e/ou de produção de conteúdos.

Já para o terceiro grupo, o que trata de particularidades dos estudos, em termos de temas sociais, o principal tema tratado nesses trabalhos foi gênero; seguido por relações de poder; questões etnico-raciais e justiça social; estereótipos e diversidade cultural; e capacitismo (a discriminação das pessoas com alguma deficiência). Indicamos, por fim, a quais dimensões críticas cada proposta pedagógica corresponde, ou seja, identificamos quais relatos discutem questões ligadas às Origens (autocrítica, ponto de vista), aos Processos (métodos participativos, horizontais, etc.) e aos Objetivos (conscientização, liberdade). A maior parte deles aborda as três; muitos incluem a crítica apenas nos métodos e alguns trabalhos envolvem duas dimensões.

Em função do destaque dado por esses estudos empíricos ao tratamento das questões de gênero, optamos por nos aprofundar no corpus composto pelos 23 estudos que focalizam essa questão. A análise desses trabalhos visou 
conhecer os recursos didáticos por eles utilizados para o desenvolvimento das habilidades TIC e para o fortalecimento da perspectiva feminista.

\subsection{Categorias Para Analisar Projetos de AMI Sobre Estereótipos e GÊNERO}

Para entender as práticas relatadas nos trabalhos ${ }^{3}$, construímos 6 categorias de análise baseadas nas teorias e pedagogias feministas. Buscamos também, na literatura sobre competências em informação, mídias e tecnologias digitais elementos de convergência com essas categorias. Esse esforço visa facilitar a identificação dos processos críticos nas práticas de ensino e reforçam a relação entre os dois referenciais teóricos desta pesquisa. São elas: ponto de vista, autocrítica; colaboração; desconstrução; empoderamento; e bem viver.

O quadro 1 organiza essas categorias, sendo a última coluna a descrição da categoria.

\section{Quadro 1 - Sistematização das categorias de análise das práticas críticas}

\begin{tabular}{|c|c|c|c|c|}
\hline $\begin{array}{l}\text { Lugar / } \\
\text { Momento }\end{array}$ & Categoria & Feminismo & AMI & Descrição \\
\hline \multirow{2}{*}{$\begin{array}{l}\text { ORIGEM / } \\
\text { INÍCIO }\end{array}$} & Ponto de vista & $\begin{array}{l}\text { Lugar de fala, saber } \\
\text { localizado, parcialidade, } \\
\text { ancestralidade, } \\
\text { corporeidade }\end{array}$ & Contexto & $\begin{array}{l}\text { Partimos de um corpo, de um lugar, de } \\
\text { uma experiência, de uma temporalidade } \\
\text { e de uma ancestralidade. Esse é nosso } \\
\text { contexto sócio-histórico de atuação, o } \\
\text { nosso ponto de vista inicial. }\end{array}$ \\
\hline & Autocrítica & $\begin{array}{l}\text { Autocrítica; } \\
\text { autorreflexão; } \\
\text { autoavaliação }\end{array}$ & $\begin{array}{l}\text { Aprender a } \\
\text { aprender, } \\
\text { metacognição }\end{array}$ & $\begin{array}{l}\text { Questionamos nossos próprios } \\
\text { mecanismos cognitivos, nossos } \\
\text { preconceitos/estereótipos. } \\
\text { Compreendemos nossos modos de } \\
\text { pensar, sentir e aprender. }\end{array}$ \\
\hline $\begin{array}{l}\text { PROCESSO } \\
\text { / MEIO }\end{array}$ & Colaboração & $\begin{array}{l}\text { Comunidade, } \\
\text { coletividade, } \\
\text { diversidade, } \\
\text { cooperação, } \\
\text { horizontalidade, escuta, } \\
\text { troca, inclusão }\end{array}$ & $\begin{array}{l}\text { Academia como } \\
\text { conversa; } \\
\text { negociação de } \\
\text { significados }\end{array}$ & $\begin{array}{l}\text { Se temos um ponto de vista localizado, é } \\
\text { ouvindo, trocando, incluindo e } \\
\text { colaborando de forma horizontal com } \\
\text { pessoas diversas, com generosidade e } \\
\text { empatia, que ampliamos nosso saber. }\end{array}$ \\
\hline
\end{tabular}

\footnotetext{
${ }^{3}$ Apesar de serem o coração da pesquisa, não há espaço hábil neste texto para listar, resumir ou realizar as análises dos 23 trabalhos, disponíveis para consulta no texto integral da tese. Aqui, optamos por oferecer um panorama global da pesquisa, apresentando seus resultados e conclusões.
} 


\begin{tabular}{|c|c|c|c|c|}
\hline $\begin{array}{l}\text { Lugar / } \\
\text { Momento }\end{array}$ & Categoria & Feminismo & AMI & Descrição \\
\hline & Desconstrução & $\begin{array}{l}\text { Do Patriarcado (e } \\
\text { outros sistemas de } \\
\text { opressão) }\end{array}$ & $\begin{array}{l}\text { Informação/mí } \\
\text { dias/tecnologia } \\
\text { s são } \\
\text { construídas } \\
\text { socialmente }\end{array}$ & $\begin{array}{l}\text { Compreendemos a estrutura dos } \\
\text { sistemas de opressão, a construção social } \\
\text { da informação/mídias/tecnologias e } \\
\text { como elas podem reproduzir ou } \\
\text { desconstruir esses sistemas. }\end{array}$ \\
\hline \multirow{2}{*}{$\begin{array}{l}\text { OBJETIVO / } \\
\text { FIM }\end{array}$} & Empoderamento & $\begin{array}{l}\text { Entusiasmo, Auto- } \\
\text { estima, } \\
\text { Conscientização }\end{array}$ & $\begin{array}{l}\text { Autonomia; } \\
\text { auto-confiança; } \\
\text { capacidade de } \\
\text { decisão e de } \\
\text { avaliação }\end{array}$ & $\begin{array}{l}\text { Nos empoderamos, qu é o objetivo dos } \\
\text { processos educativos e sociais: o } \\
\text { desenvolvimento pleno da pessoa em sua } \\
\text { subjetividade e potencialidade. }\end{array}$ \\
\hline & Bem viver & $\begin{array}{l}\text { Equidade de } \\
\text { oportunidades, justiça } \\
\text { social, continuum de } \\
\text { resistência }\end{array}$ & $\begin{array}{l}\text { Ética, } \\
\text { Aprendizado ao } \\
\text { longo da vida }\end{array}$ & $\begin{array}{l}\text { Objetivo final: nos tornamos pessoas } \\
\text { conscientes que podem contribuir para } \\
\text { uma sociedade (e uma academia) mais } \\
\text { justa e feliz. E sabemos que esse é um } \\
\text { trabalho contínuo. }\end{array}$ \\
\hline
\end{tabular}

Fonte: Elaborado pela autora (2021)

Essas seis categorias foram nossas chaves para procurar entender de que forma o ensino de competências em informação, mídias e tecnologias digitais, quando informados por princípios críticos, pode se aliar à desconstrução do patriarcado e, com ele, os estereótipos de gênero.

\subsection{Resultados: Como Desconstruir Estereótipos de GÊNero?}

Trazemos aqui um exemplo de prática de ensino para cada categoria. Para representar a categoria ponto de vista, voltamos a atenção para o trabalho sobre bibliografias multimídias de Katherine Batchelor (2019). A autora mostra como as referências de uma disciplina informam o debate e propõe como trabalho final a compilação de conjuntos de referências multimídias, pensadas para promover justiça social. Uma das estudantes compila referências sobre a cultura do estupro a partir do ponto de vista da vítima, raramente priorizado.

Para exemplificar como a autocrítica ajuda a desconstruir estereótipos de gênero, selecionamos o trabalho de Vivian Bynoe e Anne Katz (2018), parceria entre bibliotecária e professora de pedagogia para promover técnicas de leitura crítica com docentes em formação. O livro adotado fala sobre uma jovem muçulmana que decide usar o véu e dentre as atividades de análise do texto foi 
incluído um questionamento sobre quais estereótipos o livro desmonta e quais ele reforça, que coloca a necessidade de constante questionamento.

A colaboração aparece no projeto de produção de vídeos de Diane Watt (2019). A autora trabalha com estudantes de pedagogia sobre sua inclusão da produção de vídeos no currículo escolar. Ela dá como exemplo um plano de aula sobre estereótipos em publicidades para crianças, em que elas debatem os papéis de gênero e são motivadas a cria um comercial que quebre essas expectativas.

Para exemplificar o processo de desconstrução, o trabalho de Sherell MacArthur (2019) com meninas negras parte da constatação que, apesar da diversidade da população nos USA, a língua inglesa continua a ser ensinada a partir de textos e valores de homens brancos. A professora criou um coletivo de estudos depois da escola com adolescentes para analisar os estereótipos de mulheres negras e ajudá-las a produzir contranarrativas.

A categoria empoderamento é central no trabalho sobre o cineclube de Theresa Redmond (2012). A autora propõe uma abordagem chamada "pedagogia da satisfação crítica", que envolve horizontalidade, conscientização e diversão. O programa de debates termina com o "Dia do Empoderamento" que acontece na sequência do dia da desconstrução de estereótipos de homens/meninos e do dia das mulheres/meninas. O grupo vê vídeos sobre propaganda e consumo e começa a preparar seus projetos de vídeo.

Para a última categoria, o bem viver, trazemos o estudo sobre os posters digitais de Ted Kesler, Pablo Tinio e Brian Nolan (2016). Os autores trabalham com cultura pop para mobilizar adolescentes com dificuldades de aprendizado para a leitura crítica e o uso das mídias digitais enquanto se divertem. $\mathrm{O}$ artigo detalha o caso de uma estudante cujo trabalho mostra meninas adolescentes focadas nos estudos e contribuindo para suas comunidades, em contraponto à ideia geral de futilidade e inconsequência.

\section{CONSIDERAÇÕES FINAIS}

O que podemos afirmar a partir dos resultados dessa pesquisa é que uma prática, para ser considerada crítica e feminista deve atentar para seu ponto de 
vista inicial, fazer uma contínua autocrítica, ser colaborativa, promover a desconstrução de discursos opressores, empoderar pessoas e buscar promover o bem viver na sociedade. Os resultados indicam que o objetivo principal, a saber, identificar evidências que indiquem de que forma podemos desconstruir estereótipos de gênero a partir de práticas de ensino de competências AMI, foi alcançado.

O trabalho estreita laços da Ciência da Informação com áreas irmãs, Comunicação e Computação, ao proceder ao mapeamento das experiências de ensino das literacias que envolvem as TICs nessas áreas acadêmicas. Ao mapear as práticas de ensino dessas competências informacionais com perspectiva crítica, este trabalho reforça a necessidade da generalização de uma educação voltada para o relacionamento consciente e responsável com a informação, as mídias e as tecnologias digitais, cujo objetivo é a justiça social. $\mathrm{Na}$ qualidade de um trabalho feminista, esta pesquisa também reforça a posição dos Estudos e Gênero dentro do campo da Ciência da Informação e vice-versa.

Concluímos ressaltando o ineditismo do trabalho de reunião de estudos aplicados e críticos que, ao invés de teorizar abstratamente ou apontar deficiências nas práticas atuais de AMI, buscou atuar de forma propositiva. Essa valorização de boas práticas, um dos direcionamentos propostos por Belluzzo (2017) para o campo, chama a atenção para a diversidade e a qualidade de projetos que conseguem fomentar a busca por justiça social e promover a desconstrução de estereótipos de gênero por meio da informação.

\section{REFERÊNCIAS}

ARAÚJO, C. A. Á. Arquivologia, biblioteconomia, museologia e ciência da informação: o diálogo possível. Brasília: Briquet de Lemos; São Paulo: ABRAINFO, 2018.

AUFDERHEIDE, P. Media literacy: a report of the national leadership conference on media literacy. Washington, D.C.: The Aspen Institute, 1993.

BARDIN, L. Análise de conteúdo. Tradução: Luís Antero Reto e Augusto Pinheiro. São Paulo: Edições 70, 2011. 
BATCHELOR, K. E. Using linked text sets to promote advocacy and agency through a critical lens. Journal of Adolescent \& Adult Literacy, v. 62, n. 4, p. 379- 386, jan./feb. 2019.

BATISTA, L. S.; MATTOS, L. Sem atalhos: transformando o discurso em ações efetivas para promover a liderança feminina. São Paulo: Bain \& Company, 2019.

BELLUZZO, R. C. B. O estado da arte da Competência em Informação (Colnfo) no Brasil: cenários e espectros: relatório de trienal de pesquisa. Marília: Unesp, 2017.

BRISOLA, A. C.; ROMEIRO, N. L. A competência crítica em informação como resistência: uma análise sobre o uso da informação na atualidade. RBBD:

Revista Brasileira de Biblioteconomia e Documentação, São Paulo, v. 14, n. 3, p. 68-87, set. 2018.

BYNOE V.; KATZ, A. Thinking outside the box: a critical literacy collaborative. Reference Services Review, v. 46, n. 2, jun. 2018.

CAMPELLO, B. O movimento da competência informacional: uma perspectiva para o letramento informacional. Ciência da Informação, Brasília, v. 32, n. 3 , fev. 2003.

CAPURRO, R. Epistemologia e Ciencia da Informação. In: ENCONTRO NACIONAL DE PESQUISA EM CIÊNCIA DA INFORMAÇÃO (ENANCIB), 5., 2003, Belo Horizonte. Anais [...]. Belo Horizonte: UFMG, 2003.

D'AMORIM, M. A. Estereótipos de gênero e atitudes acerca da sexualidade em estudos sobre jovens brasileiros. Temas em Psicologia, v. 5, n. 3, p. 121-134, dez. 1997.

DOYLE, A. Competências em informação, mídia e tecnologias digitais e a desconstrução de estereótipos de gênero: práticas de ensino críticas. 2021. 218 f. Tese (Doutorado em Ciência da Informação) - Escola de Comunicação, Universidade Federal do Rio de Janeiro; Instituto Brasileiro de Informação em Ciência e Tecnologia, Rio de Janeiro, 2021.

DOYLE, A.; DODEBEI, V. Mapa Teórico Conceitual para construção de categorias em projetos transdisciplinares. In: CONGRESSO ISKO ESPANHAPORTUGAL, 5., 2021, Lisboa. (15이으. ISKO España). Anais [...] Lisboa, 2021. p. 535-542.

DODEBEI, V. O sentido e o significado de documento para a Memória Social. 1997. Tese (Doutorado em Comunicação) - Universidade Federal do Rio de Janeiro, Rio de Janeiro, 1997.

DUDZIAK, E. A. Information literacy: princípios, filosofia e prática. Ciência da Informação, Brasília, v. 32, n. 1, p. 23-35, jan./abr. 2003. 
ELMBORG, J. Critical information literacy: implications for instructional practice. The Journal of Academic Librarianship, v. 32, n. 2, p. 192-199, mar. 2006.

FRANCO, A. Marielle Franco: pensadora, ativista e política negra 1979-2018. Rio de Janeiro, 2020. (Curso Pensadoras Negras 1. ed.). Slides de Aula.

FRAU-MEIGS, D. Transliteracy as the new research: horizon for media and information literacy. Medijske Studije, v. 3, n. 6, p. 14-27, 2012.

FREIRE, P. Pedagogia do oprimido. Rio de Janeiro: Paz e Terra, 1987.

HARAWAY, D. Situated knowledges: the science question in feminism and the privilege of partial perspective. Feminist Studies, v. 14, n. 3, p. 575-599, 1988.

HATSCHBACH, M. H. de L.; OLINTO; G. Competência em informação: caminhos percorridos e novas trilhas. Revista Brasileira de Biblioteconomia e Documentação, São Paulo, v. 4, n. 1, p. 20-34, jan./jun. 2008.

HEINZ, M. Systematic Mapping Studies. 2014. (Slides, online). Disponível em: https://userpages.uni-koblenz.de/ laemmel/esecourse/slides/sms.pdf. Acesso em: 10 maio 2021.

HOOKS, B. Ensinando a transgredir: a educação como prática de liberdade. São Paulo: Martins Fontes, 2019.

KESLER, T.; TINIO, P. P. L.; NOLAN, B. T. What's our position? a critical media literacy study of popular culture websites with eighth-grade special education students. Reading \& Writing Quarterly, v. 32, n. 1, p. 1-26, 2016.

LIVINGSTONE, S. Media literacy and the challenge of new information and communication technologies. The Communication Review, v. 7, n. 1, p. 3-14, 2004.

LOURO, G. L. Gênero, sexualidade e educação: uma perspectiva pósestruturalista. Petrópolis: Vozes, 1997.

McARTHUR, S. A. Centering student identities in critical media literacy instruction. Journal of Adolescent \& Adult Literacy, v. 62, n. 6, p. 686-689, May/June 2019.

PAREDES, J. Despatriarcalización: uma respuesta categórica del feminismo comunitario. Revista de Estudios Bolivianos, v. 21, p. 101-115, 2015.

PETTICREW, M.; ROBERTS, H. Systematic reviews in the social sciences: a practical guide. Estados Unidos: Blackwell Publishing, 2006.

POOL, C. R. A new digital literacy: a conversation with Paul Gilster. IntegratingTechnology into Teaching, v. 55, n. 3, nov. 1997. 
REDMOND, T. The pedagogy of critical enjoyment: teaching and reaching thehearts and minds of adolescent learners through media literacy education. Journal of Media Literacy Education, v. 4, n. 2, p. 106-120, 2012.

RIBEIRO, D. O que é lugar de fala?. Belo Horizonte: Letramento, 2017.

ROSA, B. A transdisciplinariedade das literacias emergentes no contemporâneo conectado: um mapeamento do universo documental das literacias de mídia e informação (MIL). 2016. 183 f. Dissertação (Mestrado em Ciências da Comunicação) - Escola de Comunicação e Artes, Universidade de São Paulo, São Paulo, 2016.

SAFFIOTI, H. I. B. Gênero, patriarcado e violência. São Paulo: Editora Perseu Abramo, 2011.

SCOTT, J. Gênero: uma categoria útil de análise histórica. Educação \&Realidade, v. 20, n. 2, p. 71-99, jul./dez. 1995.

TEWELL, E. A decade of critical information literacy. Communications in Information Literacy, v. 9, n. 1, p. 24-43, 2015.

UNESCO. Declaração de Grünwald: sobre educação para os media. Grünwald (Alemanha): UNESCO, 1982.

UNESCO. Media and information literacy (MIL). Paris: UNESCO, 2010.

VITORINO, E. V.; PIANTOLA, D. Competência informacional - bases históricas e conceituais: construindo significados. Ciência da Informação, Brasília, v. 38, n. 3, p. 130-141, set./dez. 2009.

WATT, D. Video Production in Elementary Teacher Education as a Critical Digital Literacy Practice. Media and Communication, v. 7, n. 2, p. 82-99, 2019.

\title{
CRITICAL INSTRUCTION PRACTICES OF INFORMATION, MEDIA AND DIGITAL LITERACIES AND THE DECONSTRUCTION OF GENDER STEREOTYPES
}

\begin{abstract}
Objective: The work The work presents a synthesis of the doctoral thesis that aimed to understand how information, media and digital literacies are taught in order to favor the deconstruction of gender stereotypes. Methodology: The methods used in empirical research were Systematic Literature Review and Content Analysis, with analytical categories constructed from the transdisciplinary method Theoretical Conceptual Map. Results: The results include an international overview of 65 critical teaching practices, as well as an analysis of the 23 practices of critical literacies that also include stereotypes and gender. Conclusions: It concludes that in order to deconstruct gender stereotypes through the teaching of information, media and digital literacies, it is necessary to promote activities that consider different points of view, promote self-criticism, are
\end{abstract}


collaborative, aimed at deconstructing oppression, favor empowerment and encompass a continuous struggle for social justice and living well among people and with nature.

Descriptors: Information Literacy. Gender Stereotype. Critical literacy practices. Feminism.

\title{
PRACTICAS DE ALFABETIZACIÓN INFORMACIONAL, MEDIÁTICA Y DIGITAL Y LA DESCONSTRUCCIÓN DE ESTEREOTIPOS DE GÉNERO
}

\begin{abstract}
RESUMEN
Objetivo: El trabajo presenta una síntesis de la tesis doctoral que tuvo como objetivo comprender cómo se enseñan las habilidades en información, medios y tecnologías digitales para favorecer la deconstrucción de los estereotipos de género.. Metodología: Los métodos utilizados en el enfoque empírico incluyen la Revisión Sistemática de la Literatura y el Análisis de Contenido, con categorías analíticas construidas a partir del método transdisciplinario del Mapa Teórico-Conceptual. Resultados: Los resultados incluyen un panorama internacional de 65 prácticas de enseñanza críticas, así como un análisis de 23 prácticas de enseñanza que también trabajan con estereotipos y género. Conclusiones: El análisis de datos nos permite concluir que para deconstruir estereotipos de género a través de la enseñanza de la alfabetización informacional, mediatica y digital, se necesitan actividades que consideran diferentes puntos de vista, promueven la autocrítica, son colaborativas, orientadas a deconstruir la opresión, favorecer el empoderamiento y abarcar una lucha permanente por la justicia social y el buen vivir entre las personas y con la naturaleza.
\end{abstract}

Descriptores: Alfabetización informacional. Estereotipo de género. Prácticas de enseñanza críticas. Feminismo.

Recebido em: 19.08.2021

Aceito em: 22.12.2021 